\title{
Cecal Colonization and Systemic Spread of Candida albicans in Mice Treated with Antibiotics and Dexamethasone
}

\author{
CATHERINE M. BENDEL, STEPHEN M. WIESNER, ROBB M. GARNI, \\ ELIZABETH CEBELINSKI, AND CAROL L. WELLS \\ Departments of Pediatrics [C.M.B., E.C.], Laboratory Medicine and Pathology [S.M.W., R.M.G., C.L.W.], \\ and Surgery [C.L.W.], University of Minnesota, Minneapolis, Minnesota 55455, U.S.A.
}

\begin{abstract}
Infections with Candida albicans have become a significant problem among very low birth weight infants in the neonatal intensive care unit. Risk factors are multiple and include administration of antibiotics and glucocorticoids, such as dexamethasone. Experiments were designed to study the combined effect of oral broad-spectrum antibiotics and parenteral dexamethasone on cecal colonization and extraintestinal dissemination of C. albicans in separate groups of mice that were orally inoculated with one of four C. albicans strains that were either wild-type INT1/ INT1 or had one or more disruptions of the INT1 gene. Intestinal colonization was monitored by quantitative culture of the mouse cecum, and extraintestinal invasion was monitored by quantitative culture of the draining mesenteric lymph nodes and kidneys. At sacrifice, the average numbers of cecal $C$. albicans differed from $7.7 \log _{10} / \mathrm{g}$ to $6.7 \log _{10} / \mathrm{g}(p<0.01)$ in mice orally inoculated with $C$. albicans containing two functional copies of $I N T 1$ and no functional copies of INT1, respectively. The inci-
\end{abstract}

\section{ABSTRACT}

dence of extraintestinal dissemination to mesenteric lymph nodes and kidneys correspondingly varied from 57 to $13 \%(p<0.01)$ and 83 to $4 \%(p<0.01)$ in mice inoculated with these two $C$. albicans strains. Mice orally inoculated with $C$. albicans containing one functional copy of INTI had intermediate levels of cecal colonization and extraintestinal dissemination. Thus, cecal colonization and extraintestinal dissemination of $C$. albicans was facilitated in antibiotic-treated mice given dexamethasone. In addition, the presence of two functional copies of the INT1 gene was associated with the greatest levels of cecal colonization and extraintestinal dissemination of C. albicans. (Pediatr Res 51: 290-295, 2002)

VLBW, very low birth weight

NICU, neonatal intensive care unit

MLN, mesenteric lymph nodes
Candida albicans is the most prevalent fungal pathogen in clinical disease (1), particularly among VLBW infants in the NICU (2-5). Among NICU patients, the incidence of systemic candidiasis appears to be rising dramatically (6). More than a decade ago, between 1.5 and $4.5 \%$ of VLBW infants developed a systemic Candida infection (2, 3, 7, 8). However, a recent study found an 11-fold increase in one nursery between 1981 and 1995 (9). Among hospitals participating in the United States National Nosocomial Infection Survey, Candida species represented the sixth most common nosocomial pathogen, accounting for $7 \%$ of all bloodstream infections, with $C$. albicans the most frequent species isolated $(1,10)$. In the general patient population, overall mortality caused by systemic candidiasis remains high, ranging from 63 to $85 \%$ in

Received May 17, 2001; accepted November 9, 2001.

Correspondence and reprint requests: Catherine M. Bendel, M.D., Department of Pediatrics, Division of Neonatology, University of Minnesota, Mayo Mail Code 39, 420 Delaware Street SE, Minneapolis, MN 55455, U.S.A.; e-mail: bende001@tc.umn.edu

Supported by Public Health Service grant GM 59221 from the National Institutes of Health and grant \#FY00-417 from the March of Dimes Birth Defects Foundation. untreated patients and from 33 to $54 \%$ in those receiving appropriate antifungal therapy [reviewed by Todischini (11)]. Morbidity is also high, and multiple extensive complications often accompany candidemia, including meningitis, renal insufficiency or failure, endophthalmitis, pulmonary abscesses, endocarditis, and osteomyelitis $(2,3,7,12,13)$.

C. albicans is a commensal in the human gastrointestinal tract $(14,15)$, and it is generally accepted that increased intestinal colonization is a major factor predisposing high-risk patients to systemic candidiasis $(12,14,16)$. Other risk factors for systemic candidiasis include prematurity, broad-spectrum antibiotics, abdominal surgery, neutropenia, vascular catheters, mesenteric ischemia, damage to the gastrointestinal mucosa, total parenteral nutrition, and corticosteroids $(1,12,16)$. In the past decade, there has been a significant increase in the use of glucocorticoids (particularly i.v. dexamethasone) in the NICU $(17,18)$, and this practice is coincident with the increase in $C$. albicans infections $(7,19)$. Although dramatic physiologic improvement in pulmonary function can been seen almost immediately with the use of steroids in premature infants, both 
short-term and long-term adverse affects, including increased risk of infection, are now being documented [(20), also reviewed by Jobe (21)].

In addition to host risk factors, a variety of microbial factors have been implicated in C. albicans virulence, including variable phenotypic expression, morphologic switching, molecular mimicry, expression of various surface molecules (e.g. receptors, adhesins), hydrophobicity, thigmotropism, and production of proteinase and phospholipase $(14,15,22-24)$. Using a method for sequential disruption of the INT1 gene $(25,26)$, mutant strains have been generated and used to show that the INT1 gene product contributes to C. albicans adherence to HeLa cells, mortality in i.v. inoculated mice, and filamentous growth on specific agar media known to facilitate filamentation (27-29). We have also shown that the presence of two functional copies of the INT1 gene facilitates intestinal colonization in the orally inoculated mouse, but no dissemination (translocation) to normally sterile extraintestinal sites was observed (30). This observation is likely not related to differences in filamentation because these C. albicans INT1 mutant strains appear to filament normally in vivo $(27,31)$ and in serumcontaining liquid media $(28,29)$. In the present study, we used C. albicans INT1 mutant strains to investigate the effect of dexamethasone on extraintestinal spread of C. albicans in antibiotic-treated mice.

\section{METHODS}

C. albicans strains and cultivation conditions. The parent C. albicans strain CAF2 (INT1/INT1 URA3/ura3::imm434) was obtained from W.A. Fonzi (Georgetown University, Washington, DC, U.S.A.) (26). Using the urablaster method, $C$. albicans strains were constructed with disruptions and reintegrations in the INT1 gene, and C. albicans CAG1 (INT1/int1::hisG-URA3-hisG ura3::imm434/ura3::imm434), C. albicans CAG3 (int $1:$ hisG/int 1::hisG-URA3-hisG ura3::imm 434/ura3::imm434), and C. albicans CAG5 (int $1:$ hisG/int $1:$ hisG $: \because$ INT1-URA3) have been previously described $(28,29)$. The parent CAF2 (INT1/INT1) demonstrates extensive hyphal development on agar media known to stimulate filamentation, maximal adhesion to cultured epithelial cells, and maximal mortality in i.v. inoculated mice (28). The null mutation CAG3 (int1/int1) has markedly reduced hyphal formation on these agar media; minimal adherence to cultured epithelial cells, and minimal mortality in i.v. inoculated mice (28). The heterozygous deletion strain CAG1 (INT1/int1) and the heterozygous reintegrant CAG5 (int1/int1 + INT1) have an intermediate phenotype compared with CAF2 (INT1/INT1) and CAG3 (int1/int1) with respect to both adhesion to cultured epithelium and virulence. Compared with CAF2, all three mutant strains (CAG1, CAG3, CAG5) have decreased ability to colonize the gastrointestinal tract of antibiotic-treated mice $(30,31)$. It should be noted that CAF2, CAG1, CAG3, and CAG5 have similar growth rates, i.e. generation times, in broth medium, and that URA3/ura3 strains were used in experiments (29). For clarity in this manuscript, C. albicans CAF2 (INT1/ INT1), CAG1 (INT1/int1), CAG3 (int1/int1), and CAG5 (int1/ int $1+I N T 1)$ are referred to as C. albicans $+/+,-/+,-/-$, and $-/-/+$ reflecting two functional copies of $I N T 1$, a single gene disruption, a double gene disruption, and a double gene disruption with subsequent reintegration of one functional copy of $I N T 1$, respectively.

C. albicans stock cultures were maintained at $-80^{\circ} \mathrm{C}$ in Sabouraud's dextrose broth (Difco Laboratories, Detroit, MI, U.S.A.) supplemented with $15 \%$ glycerol. For use in experiments, stock cultures were plated on minimal medium agar supplemented with $2 \%$ dextrose, incubated at $30^{\circ} \mathrm{C}$ for $48 \mathrm{~h}$, inoculated into minimal medium dextrose broth, and incubated at $30^{\circ} \mathrm{C}$ with shaking for $18 \mathrm{~h}(28,29)$. The $C$. albicans strains used in this study grew exclusively as yeast cells (blastoconidia) under these conditions. Yeast cells were washed and resuspended in sterile saline at $10^{8} / \mathrm{mL}$ for oral inoculation into mice. Inoculum concentration was determined by hemocytometer and verified by quantitative culture on Sabouraud's dextrose agar incubated $48 \mathrm{~h}$ at $30^{\circ} \mathrm{C}$.

Experimental treatment of mice. Adult, female (18 to $22 \mathrm{~g}$ ) Swiss Webster mice were purchased from Harlan SpragueDawley (Indianapolis, IN, U.S.A.). In each of two replicate experiments, 48 mice were divided into four groups of 12 mice and orally inoculated (feeding needle) with $0.1 \mathrm{~mL}$ containing $10^{7}$ C. albicans $+/+,-/+,-/-$, or $-/-/+$. To facilitate intestinal colonization, mice were given $1 \mathrm{mg} / \mathrm{mL}$ bacitracin (Sigma Chemical Co., St. Louis, MO, U.S.A.), $2 \mathrm{mg} / \mathrm{mL}$ streptomycin sulfate (Sigma Chemical Co.), and $0.1 \mathrm{mg} / \mathrm{mL}$ gentamicin sulfate (Sigma Chemical Co.) in the drinking water for $3 \mathrm{~d}$ before oral inoculation with C. albicans $(31,32)$. Mice were also injected i.p. twice daily with $0.5 \mathrm{~mL}$ of $4 \mathrm{mg} / \mathrm{mL}$ (2 $\mathrm{mg}$ BID or approximately $100 \mathrm{mg} / \mathrm{kg}$ BID) dexamethasone sodium phosphate (Elkins-Sinn, Cherry Hill, NJ, U.S.A.) on the day of oral inoculation with C. albicans, and for three subsequent days. Mice were killed on the fourth day after oral C. albicans for quantitative determination of cecal microbes, and extraintestinal dissemination (translocation) of C. albicans to the MLN and kidneys. Antibiotics were continued for the duration of the experiment. A preliminary experiment showed that BID i.p. injections of $0.5 \mathrm{~mL}$ of saline, rather than dexamethasone, resulted in no extraintestinal dissemination of C. albicans $+/+$ in this model. Also, we have previously noted that in mice similarly treated with antibiotics and oral $C$. albicans (but not dexamethasone), extraintestinal dissemination of C. albicans occurs only in occasional (three of 124) mice (30).

According to the package insert, the $\mathrm{LD}_{50}$ for this preparation of dexamethasone (injected parenterally) is approximately $800 \mathrm{mg} / \mathrm{kg}$ in adult female mice. Thus, mice were given a high dose of dexamethasone in this study, i.e. $100 \mathrm{mg} / \mathrm{kg}$ BID. Others have used similarly high doses to facilitate systemic infection with $C$. albicans in rodents $(33,34)$. Our primary aim was to use dexamethasone to induce systemic spread of $C$. albicans, and lower doses were not tested. Mice and humans have different pharmacokinetics and often much higher concentrations $(\mathrm{mg} / \mathrm{kg})$ of an agent must be used to achieve a blood level comparable to that obtained in a human. However, it should be noted that we cannot assume that the dose of dexamethasone used in this study has clinical relevance for humans. 
Mice were housed under controlled conditions and handled by specially trained personnel. Using PCR to identify the genotype of $C$. albicans strains recovered from mouse ceca, these conditions have been shown to eliminate crosscontamination of inoculated strains among mouse treatment groups $(30,31)$. Experiments were performed according to the National Institutes of Health guidelines on the use of experimental animals. The University of Minnesota Institutional Animal Care and Use Committee approved all protocols.

Recovery of $\mathrm{C}$. albicans from mouse ceca, MLN, and kidneys. Although C. albicans can colonize all portions of the gastrointestinal tract, colonization is typically maximal in the cecum of the adult mouse, and the cecum is most often used to monitor candida colonization in mice $(32,35-39)$. Mice were killed by cervical dislocation, ceca were aseptically excised from four mice (randomly chosen) in each treatment group in each of the two replicate experiments. Each cecum was weighed, homogenized, serially diluted, plated on agar media, and incubated at $35^{\circ} \mathrm{C}$ for $48 \mathrm{~h}$ (33). Agar media included colistin-nalidixic acid agar supplemented with 5\% sheep red blood cells for selective isolation of Gram-positive bacteria and yeast, MacConkey agar for selective isolation of Gramnegative bacilli, and synthetic minimal medium agar (40) without uracil for cultivation of yeast containing the URA3 gene. The lower limit of assay detection was $3.0 \log _{10} / \mathrm{g}$ of cecum. Cecal tissue was not processed for strictly anaerobic bacteria because this antibiotic regimen reliably eliminates all detectable cecal anaerobic bacteria $(41,42)$.

To visualize in vivo morphology of $C$. albicans strains, cecal contents were analyzed from all mice. Cecal contents were rinsed from tissue with a minimal volume $(1-2 \mathrm{~mL})$ of sterile saline solution, and a minimal volume $(100-200 \mu \mathrm{L})$ was stained with calcofluor according to manufacturer's directions (Fungi-Fluor Kit, Polysciences, Inc., Warrington, PA, U.S.A.). (The remaining tissue and contents were used for quantitative culture as described above.) Specimens were examined under epifluorescent microscopy. Fungal elements (100/mouse from each of eight mice per treatment group) were identified as either yeast or filamentous forms, the latter defined as an outgrowth four times the width of the mother cell or a chain of four or more elongated yeast cells.

All surviving mice were monitored for extraintestinal dissemination of intestinal microbes by culturing the draining MLN, as well as the kidneys. Before excision of the cecum, the MLN and kidneys were aseptically excised, homogenized, and quantitatively cultured as described $(33,39)$. Tissue homogenates were plated on tryptic soy agar supplemented with $5 \%$ sheep red blood cells and minimal medium agar without uracil. The lower limits of microbial detection were 5 per MLN (entire tissue) and $1.3 \log _{10} / \mathrm{g}$ of kidney.

Microbes were identified by standard techniques (43). Identification of $C$. albicans was confirmed by Gram's stain, coupled with observation of characteristic hyphal formation after incubation of yeast cells in rabbit serum incubated for $3 \mathrm{~h}$ at $37^{\circ} \mathrm{C}$. All C. albicans strains used in this study form hyphal elements, including germ tubes, in serum after $3 \mathrm{~h}$ incubation at $37^{\circ} \mathrm{C}(29)$. Using specific primers for the INT1 locus (28), PCR was performed on two colonies from each cecum and one colony from each MLN, and the genotype of the recovered $C$. albicans consistently corresponded to the inoculated strain.

Statistical analysis. Statistical analyses were performed using StatView 5.0.1 (SAS Institute, Cary, NC, U.S.A.). To verify reproducibility, the experimental protocol was repeated on two separate days. Each experiment contained 12 mice per treatment group inoculated with $C$. albicans $+/+,-/+,-/-$, or $-/-/+$, for a total of 48 mice per experiment. Cecal flora was analyzed from four mice per treatment group in each replicate experiment for a total of eight mice per treatment group. Microbial dissemination to MLN and kidneys was analyzed in all surviving mice. Numbers of tissue (cecal, MLN, kidney) C. albicans were analyzed by the Kruskal-Wallis test followed by post hoc testing using the unpaired Mann-Whitney $U$ test. Fractional data were analyzed by $\chi^{2}$ with continuity correction. $P$ values $<0.05$ were considered significant.

\section{RESULTS}

Mortality and cecal colonization. A total of 24 mice (12 mice in each of two experiments) were orally inoculated with C. albicans $+/+,-/+,-/-$, or $-/-1+$ followed by dexamethasone treatment for $4 \mathrm{~d}$. Occasional mortality was observed, i.e. one mouse inoculated with $-/-$ and three mice inoculated with $-/+$, but there were no significant differences in mortality in mice inoculated with C. albicans $+/+,-/+$, $-/-$, or $-/-/+$. All mortality took place during the night, and these mice were unavailable for study because of the timing of their deaths. All surviving mice appeared healthy for the duration of these experiments, and there was no gross pathology at autopsy other than the cecal enlargement typical of mice given broad-spectrum antibiotics (41).

At sacrifice, mice had no detectable cecal Gram-negative bacilli, and only two mice (both inoculated with $-/+$ ) had cecal Gram-positive bacteria, identified as Micrococcus sp. in one mouse and Bacillus sp. in the other. The average concentration of cecal C. albicans $+/+,-/+,-/-$, and $-1-1+$ varied 10-fold from $7.7 \log _{10} / \mathrm{g}$ to $6.7 \log _{10} / \mathrm{g}$ for C. albicans $+/+$ and $-/-$, respectively (Fig. 1). The numbers of $C$. albicans recovered on colistin nalidixic agar were similar to those recovered on minimal medium lacking uracil, indicating that the URA3 locus (and thus the INT1 gene construct) remained stable in vivo. Data reported in Figure 1 reflect the numbers of cecal C. albicans recovered on minimal medium lacking uracil. The numbers of cecal C. albicans $+/+$ were consistently greater than each of the other three mutant strains, which did not differ from each other, except $C$. albicans $-/+$ was greater than $-/-$ at $p=0.05$. The numbers of cecal $C$. albicans $-1-1+$ were also greater than $-/-$, but this difference was not significant $(p=0.3)$. Although the $C$. albicans inocula was exclusively yeast cells, all strains formed filaments in cecal contents (Fig. 2), for which the percent filamentation (average \pm SE from eight mice per group) for C. albicans $+/+,-/+,-/-$, and $-/-/+$ was noted to be $46 \pm 4 \%, 19 \pm$ $5 \%, 19 \pm 6 \%$, and $43 \pm 5 \%$, respectively.

Extraintestinal dissemination. Extraintestinal dissemination of $C$. albicans was monitored by culturing the MLN and kidneys of all surviving mice. C. albicans was the only mi- 


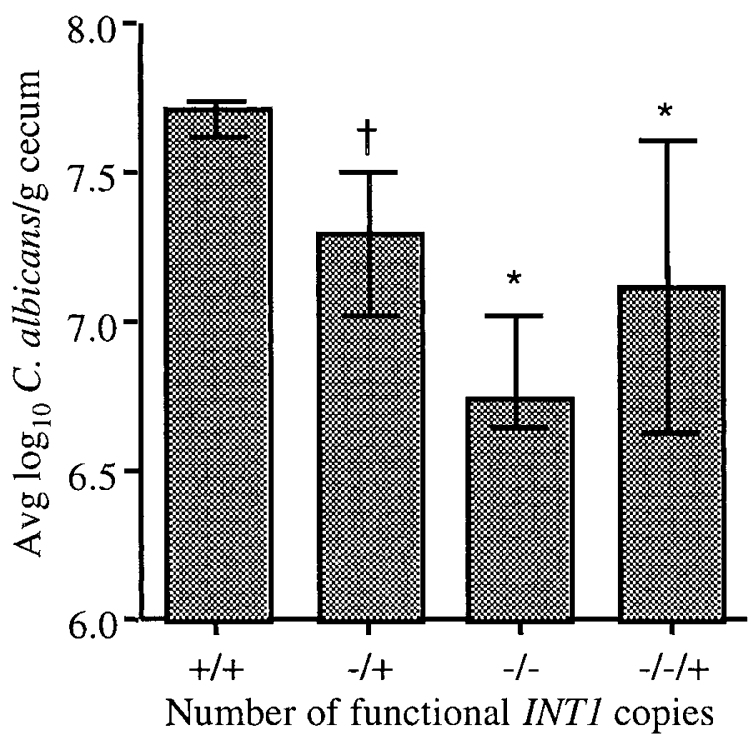

Figure 1. Effect of the number of functional INTI copies on the concentration of cecal $C$. albicans in antibiotic-treated mice orally inoculated with $C$. albicans $+/+,-1+,-1-$, or $-1-1+$ and treated with dexamethasone. Data represent eight mice per group. ${ }^{*} p<0.01 ; \dagger p<0.05$, decreased compared with mice orally inoculated with $C$. albicans $+/+$. Error bars indicate the range of data from the 25th to the 75th quartiles, and are therefore not symmetrical above and below the average value.

crobe recovered from MLN and kidneys. The incidence of $C$. albicans translocation to the MLN was highest for $C$. albicans $+/+$ and lowest for $C$. albicans $-/-$, with significant differences noted between $+/+$ and $-/+$ and between $+/+$ and $-/-$ (Table 1). Although the average number of viable $C$. albicans $+/+$ recovered from MLN was greater than the numbers of $C$. albicans $-1+,-/-$, or $-1-1+$ recovered from MLN, these differences were not significant.

Similar to the data for MLN, the numbers of mice with $C$. albicans $+/+$ recovered from kidneys was also greater than each of the three mutant strains $(-/+,-/-,-/-/+)$, which were not significantly different from each other (Table 2). Although the average number of $C$. albicans recovered from kidney tissue was greatest for $C$. albicans $-/-$, there was only one mouse with $C$. albicans $-1-$ detected in kidney tissue (reflecting the lowest incidence of C. albicans translocation among the four $C$. albicans strains tested), so this information was difficult to interpret. Compared with $C$. albicans $+/+$, there were fewer numbers of $C$. albicans $-1+$ and $-1-1+$ recovered from kidney tissue, with statistical differences of $p=$ 0.07 and $p<0.01$, respectively.

\section{DISCUSSION}

Two of the most prominent and prevalent risk factors for Candida sepsis among VLBW infants on the NICU are broadspectrum antibiotics and glucocorticoid therapy. We have previously shown that gastrointestinal colonization of the mouse by $C$. albicans was facilitated by administration of broadspectrum antibiotics (30-32). However, despite the fact that increased intestinal colonization is generally accepted as a risk factor for systemic candidiasis $(12,14,16)$, we noted only occasional extraintestinal dissemination of intestinal C. albi-
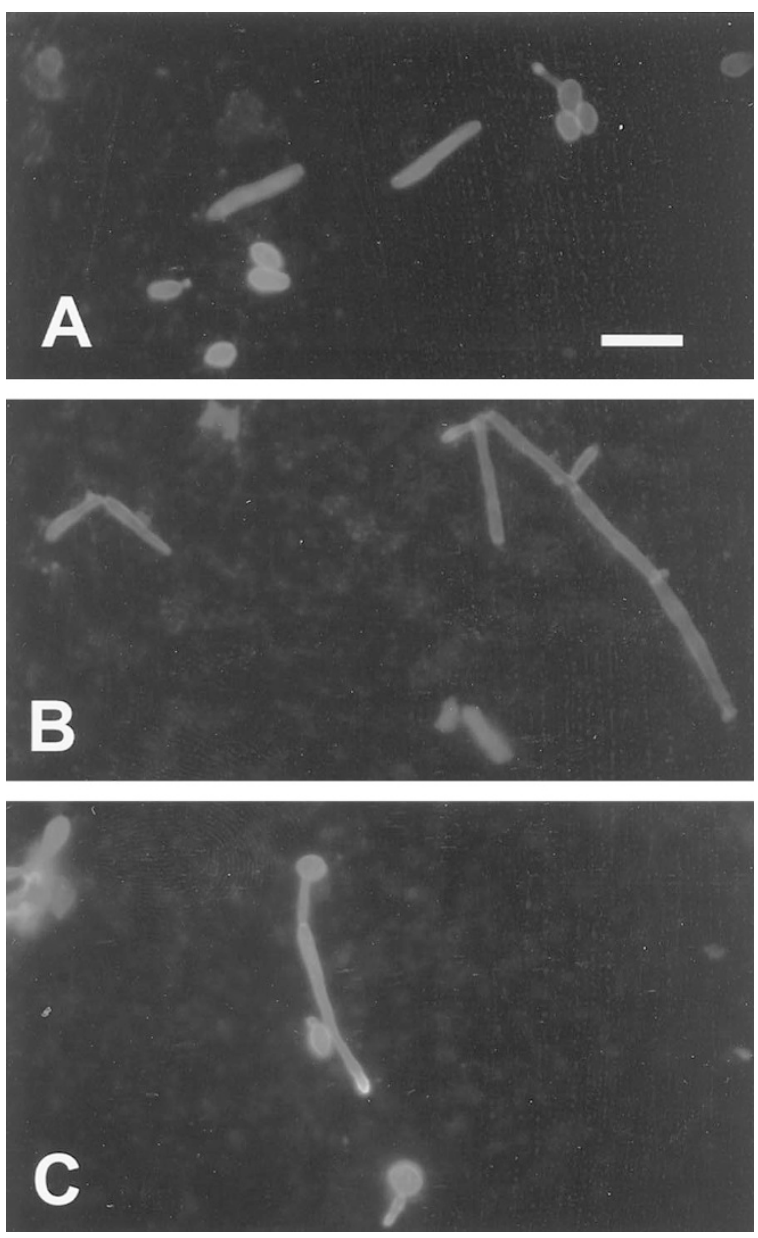

Figure 2. Calcofluor staining of cecal contents of mice colonized with $C$. albicans $+/+(A),-/-(B)$, and $-/-/+(C)$ showing presence of filamentous forms in vivo. Bar $=10 \mu \mathrm{m}$.

cans in previous studies (30). In the current study, dexamethasone appeared to facilitate cecal colonization as well as systemic spread of orally inoculated C. albicans.

For all C. albicans strains examined, the level of colonization was greater than that previously noted without the use of dexamethasone. In a previous study using the same $C$. albicans strains, oral antibiotics, and mouse strain, the average concentration of cecal C. albicans varied from $5.4 \log _{10} / \mathrm{g}$ to 3.8 $\log _{10} / \mathrm{g}$ for C. albicans $+/+$ and $-/-$, respectively (31). In the current study, addition of dexamethasone resulted in a dramatic increase (at least 100-fold) in cecal colonization to an average of $7.7 \log _{10} / \mathrm{g}$ and $6.7 \log _{10} / \mathrm{g}$ for C. albicans $+/+$ and $-/-$, respectively. Dexamethasone was also associated with increased filamentation of $C$. albicans in the intestinal tract. Without dexamethasone, the percent filamentation in cecal contents (average \pm SE) was previously reported to be $14.3 \pm$ $4.3 \%$ and $3.7 \pm 1.5 \%$ for C. albicans $+/+$ and $-/-$, respectively (32). However, in dexamethasone-treated mice, the percent filamentation was increased ( $p<0.01$, unpaired $t$ test) to $46 \pm 4 \%$ and $19 \pm 6 \%$ for C. albicans $+/+$ and $-/-$, respectively. Thus, treatment with dexamethasone appeared to facilitate both cecal colonization and filamentation of C. albicans in mouse cecal contents. 
Table 1. Translocation of $\mathrm{C}$. albicans to MLN of antibiotic-treated mice orally inoculated with $\mathrm{C}$. albicans $+/+,-/+,-/-$, or $-/-/+$ and treated with parenteral dexamethasone

\begin{tabular}{lcc}
\hline $\begin{array}{c}\text { C. albicans } \\
\text { strain }\end{array}$ & $\begin{array}{c}\text { No. mice with viable } C \text {. albicans recovered } \\
\text { from MLN/Total no. surviving mice (\%) }\end{array}$ & $\begin{array}{c}\text { Average no. of } C \text {. albicans recovered } \\
\text { from MLN of positive mice (range) }\end{array}$ \\
\hline$+/+$ & $13 / 23(57 \%)^{*}$ & $488(5-4250)$ \\
$-/+$ & $5 / 21(24 \%) \dagger$ & $104(5-375)$ \\
$-/-$ & $3 / 23(13 \%)+5(5-5)$ \\
$-/-1+$ & $8 / 24(33 \%)$ & $51(5-190)$ \\
\hline
\end{tabular}

* One MLN was not processed because of technical error.

$\dagger$ Decreased compared with C. albicans $+/+, p<0.05$.

$\ddagger$ Decreased compared with $C$. albicans $+/+, p<0.01$.

Table 2. Translocation of $\mathrm{C}$. albicans to kidneys of antibiotic-treated mice orally inoculated with $\mathrm{C}$. albicans $+/+,-/+,-/-$, or $-/-/+$ and treated with parenteral dexamethasone

\begin{tabular}{ccc}
\hline $\begin{array}{c}\text { C. albicans } \\
\text { strain }\end{array}$ & $\begin{array}{c}\text { No. mice with viable } C \text {. albicans recovered } \\
\text { from kidneys/Total no. surviving mice (\%) }\end{array}$ & $\begin{array}{c}\text { Average } \log _{10} / \mathrm{g} C \text {. albicans recovered } \\
\text { from kidneys of positive mice (range) }\end{array}$ \\
\hline$+/+$ & $20 / 24(83 \%)$ & $3.9(1.6->5.0)$ \\
$-/+$ & $4 / 21(19 \%)^{*}$ & $2.7(1.5-4.3) \dagger$ \\
$-/-$ & $1 / 23(4 \%)^{*}$ & 4.2 \\
$-/-/+$ & $6 / 24(25 \%)^{*}$ & $2.1(1.3-2.9)^{*}$ \\
\hline
\end{tabular}

* Decreased compared with C. albicans $+/+, p<0.01$.

$\dagger$ Decreased compared with C. albicans $+/+, p=0.07$.

In dexamethasone-treated mice, increased cecal colonization also was associated with systemic spread of $C$. albicans. Overall, C. albicans was recovered from the MLN of $32 \%$ of mice $(57 \%$ of those inoculated with $C$. albicans $+/+$ and $13 \%$ of those receiving $C$. albicans -/-). Systemic spread of $C$. albicans to the kidneys paralleled these numbers, i.e. $83 \%$ of the mice colonized with $C$. albicans $+/+$ showing detectable kidney involvement whereas $C$. albicans was recovered from the kidneys of only $4 \%$ of those colonized with $C$. albicans $-/-$. These data support previous studies in which the presence of two functional copies of the INT1 gene was associated with increased intestinal colonization with $C$. albicans in the orally inoculated, antibiotic-treated mouse (30-32). However, in our previous work we did not find dissemination of either the wild-type $C$. albicans or INT1 mutant $C$. albicans beyond the intestinal tract. The addition of dexamethasone led to the spread of all $C$. albicans strains, in varying degrees, to both the MLN and kidneys. It is tempting to speculate that this comparatively low incidence of translocation of the mutant $C$. albicans strains $-/+,-/-$, and $-/-/+$, compared with $C$. albicans $+/+$, might have been related to differences in the number of functional copies of the INT1 gene. However, significant differences in intestinal colonization among these strains could have been the overriding factor modulating extraintestinal dissemination of $C$. albicans $+/+,-/+,-/-$, and $-/-1+$.

In general, the data reported herein support the concerns of clinicians regarding multiple risk factors for systemic candidiasis in the VLBW infant. Even if not administered concurrently, the use of broad-spectrum antibiotics may lead to an increased level of intestinal colonization with C. albicans, which can be further augmented by glucocorticoid therapy, predisposing the premature infant (and other high-risk patient populations) to systemic candidiasis.

\section{REFERENCES}

1. Pfaller MA 1996 Nosocomial candidiasis: emerging species, reservoirs, and modes of transmission. Clin Infect Dis 22(suppl 2):S89-S94

2. Butler KM, Baker CJ 1988 Candida: an increasingly important pathogen in the nursery. Pediatr Clin North Am 35:543-563

3. Baley JE, Kleigman RM, Fanaroff AA 1984 Disseminated fungal infections in very low-birth-weight infants, clinical manifestations and epidemiology. Pediatrics $73: 144-152$

4. Benjamin Jr DK, Ross K, McKinney Jr RE, Benjamin DK, Auten R, Fisher RG 2000 When to suspect fungal infections in neonates: a clinical comparison of Candida albicans and Candida parapsilosis fungemia with coagulase-negative staphylococcal bacteremia. Pediatrics 106:712-718

5. Bendel CM, Hostetter MK 1994 Systemic candidiasis and other fungal infections in the newborn. Sem Pediatr Infect Dis 5:35-41

6. Rowen JL, Tate JM, Nordoff N, Passarell L, McGinnis MR 1999 Candida isolates from neonates: frequency of misidentification and reduced fluconazole susceptibility. J Clin Microbiol 37:3735-3737

7. Faix RG, Kovarik SM, Shaw TR, Johnson RV 1989 Mucocutaneous and invasive candidiasis among very low birth weight $(<1,500$ grams $)$ infants in intensive care nurseries: a prospective study. Pediatrics 83:101-107

8. Weese-Mayer DE, Fondriest DW, Brouillette RT, Shulman ST 1987 Risk factors associated with candidemia in the neonatal intensive care unit: a case-control study. Pediatr Infect Dis J 6:190-196

9. Kossoff EH, Buescher ES, Karlowicz MG 1998 Candidemia in a neonatal intensive care unit: trends during fifteen years and clinical features of 111 cases. Pediatr Infect Dis J 17:504-508

10. Pitter D, Wenzel RP 1995 Nosocomial blood stream infections: secular trends in rates, mortality, and contribution to total hospital deaths. Arch Intern Med 155:1177-1184

11. Todischini GT 1997 Treatment of candidiasis: a perspective on recent advances and future challenges. Int J Infect Dis 1(suppl):S37-S41

12. Odds FC 1988 Candida and Candidosis. Bailliere Tindall, London

13. Fannaroff AA, Korones SB, Wright LL, Verter J, Poland RL, Bauer CR, Tyson JE, Phillips III JB, Edwards W, Lucey JF, Catz CS, Shankaran S, Oh W, for the National Institute of Child Health and Human Development Neonatal Research Network 1998 Incidence, presenting features, risk factors, and significance of late onset septicemia in very low birth weight infants. Pediatr Infect Dis 17:593-598

14. Cutler JE 1991 Putative virulence factors of Candida albicans. Ann Rev Microbiol 45:187-218

15. Odds FC 1994 Candida species and virulence. ASM News 60:313-318

16. Cole GT, Halawa AA, Anaissie EJ 1996 The role of the gastrointestinal tract in hematogenous candidiasis: from the laboratory to the bedside. Clin Infect Dis 22(suppl 2):S73-S88

17. Bhuta T, Ohlsson A 1998 Systematic review and meta-analysis of early postnatal dexamethasone for prevention of chronic lung disease. Arch Dis Child Fetal Neonatal Ed 79:29-40

18. Finer NN, Craft A, Vaucher YE, Clark RH, Sola A 2000 Postnatal steroids: short-term gain, long-term pain? J Pediatr 137:9-13

19. Botas CM Kurlat I, Young SM, Sola A 1995 Disseminated candidal infections and intravenous hydrocortisone in preterm infants. Pediatrics 95:883-887 
20. Stoll BJ, Temprosa M, Tyson JE, Papile L, Wright LL, Bauer CR, Donovan EF, Korones SB, Lemons JA, Fanaroff AA, Stevenson DK, Oh W, Ehrenkranz RA, Shankaran S, Verter J 1999 Dexamethasone therapy increases infection in very low birth weight infants. Pediatrics [serial online] 104:e63 Available from: URL: http:// www.pediatrics.org/cgi/content/full/104/5/e63

21. Jobe AH 2000 Glucocorticoids in perinatal medicine: misguided rockets? J Pediatr 137:1-3

22. Dupont PF 1995 Candida albicans, the opportunist, a cellular and molecular perspective. J Am Podiatr Med Assoc 85:104-115

23. Shepard MG, Poulter RTM, Sullivan PA 1985 Candida albicans: biology, genetics, and pathogenicity. Ann Rev Microbiol 36:579-614

24. Hostetter MK 1996 An integrin-like protein in Candida albicans: implications for pathogenesis. Trends Microbiol 4:242-245

25. Alani E, Cao L, Kleckner NA 1987 A method for gene disruption that allows repeated use of URA3 selection in the construction of multiply disrupted yeast strains. Genetics 116:541-545

26. Fonzi WA, Irwin MY 1993 Isogenic strain construction and gene mapping in Candida albicans. Genetics 134:717-728

27. Bendel CM, Kinneberg KM, Jechorek RP, Gale CA, Erlandsen SL, Hostetter MK, Wells CL 1999 Systemic infection following intravenous inoculation of mice with Candida albicans INT1 mutant strains. Mol Genet Metab 67:343-351

28. Gale CA, Bendel CM, McClellan MA, Hauser M, Becker JM, Berman JA, Hostetter MK 1998 Linkage of adhesion, filamentous growth and virulence in Candida albicans to a single gene INTI. Science 279:1355-1358

29. Gale CA, Finkel D, Tao N, Meinke M, McClellan MA, Olson J, Kendrick K, Hostetter MK 1996 Cloning and expression of a gene encoding an integrin-like protein in Candida albicans. Proc Natl Acad Sci USA 93:357-361

30. Bendel CM, Kinneberg KM, Jechorek RP, Erlandsen SL, Sahar DE, Wells CL 2000 The Candida albicans INT1 gene facilitates cecal colonization in endotoxin-treated mice. Shock 13:453-458

31. Kinneberg KK, Bendel CM, Jechorek RP, Cebelinski EA, Gale CA, Berman JG, Erlandsen SL, Hostetter MK, Wells CL 1999 Effect of INTI gene on Candida albicans murine intestinal colonization. J Surg Res 87:245-251
32. Wiesner SM, Jechorek RP, Garni RM, Bendel CM, Wells CL 2001 Gastrointestinal colonization by Candida albicans mutant strains in antibiotic-treated mice. Clin Diagn Lab Immunol 8:192-195

33. Hurley DL, Balow JE, Fauci AS 1975 Experimental disseminated candidiasis. II. Administration of glucocorticosteroids, susceptibility to infection, and immunity. J Infect Dis 132:393-397

34. Herzyk DJ, Ruggieri E, Cunningham L, Polsky R, Herold C, Klinkner AM, Badger A, Kerns WD, Bugelski PJ 1997 Single-organism model of host defense against infection: a novel immunotoxicologic approach to evaluate immunomodulatory drugs. Toxicologic Pathol 25:351-362

35. Kennedy MJ, Volz PA 1985 Ecology of Candida albicans gut colonization: inhibition of Candida adhesion, colonization, and dissemination from the gastrointestinal tract by bacterial antagonism. Infect Immunol 49:654-663

36. Kennedy MJ, Volz PA 1985 Effect of various antibiotics on gastrointestinal colonization and dissemination by Candida albicans. J Med Vet Mycol 32:265-273

37. Ekenna O, Sheretz RJ 1987 Factors affecting colonization and dissemination of Candida albicans from the gastrointestinal tract of mice. Infect Immunol 55:15581563

38. Helstrom PB, Balish E 1979 Effect of oral tetracycline, the microbial flora and the athymic state on gastrointestinal colonization and infection of $\mathrm{BALB} / \mathrm{c}$ mice with Candida albicans. Infect Immunol 23:764-774

39. Kennedy MJ, Volz PA, Edwards CA, Yancey RJ 1987 Mechanisms of association of Candida albicans with intestinal mucosa. J Med Microbiol 24:333-341

40. Rose MD, Winston F, Heiter P 1990 Methods in Yeast Genetics. Cold Spring Harbor Press, Cold Spring Harbor, NY

41. Wells CL, Maddaus MA, Reynolds CM, Jechorek RP, Simmons RL 1987 Role of the anaerobic flora in the translocation of aerobic and facultatively anaerobic intestinal bacteria. Infect Immun 55:2689-2694

42. Wells CL, Feltis BA, Hanson DF, Jechorek RP, Erlandsen SL 1993 Oral infectivity and bacterial interactions with mononuclear phagocytes. J Med Microbiol 38:345353

43. Forbes BA, Sahm DF, Weissfeld AS 1998 Bailey and Scott's Diagnostic Microbiology, 10th Ed. CV Mosby Co, St. Louis 